\title{
Dronabinol Is a Safe Long-Term Treatment Option for Neuropathic Pain Patients
}

\author{
Sebastian Schimrigk ${ }^{\mathrm{a}}$ Martin Marziniak $^{\mathrm{b}} \quad$ Christine Neubauer $^{\mathrm{c}}$ \\ Eva Maria Kugler ${ }^{c}$ Gudrun Werner $^{c}$ Dimitri Abramov-Sommariva ${ }^{c}$ \\ a Märkische Kliniken GmbH, Klinikum Lüdenscheid, Klinik für Neurologie, Lüdenscheid, Germany; \\ ${ }^{b}$ Kbo-Isar-Amper-Klinikum München-Ost, Klinik für Neurologie, Haar, Germany; ${ }^{\mathrm{C} D e p a r t m e n t ~ C l i n i c a l ~}$ \\ Research International, Bionorica SE, Neumarkt, Germany
}

\section{Keywords}

Tetrahydrocannabinol · Neuropathic pain · Safety .

Long-term · Multiple sclerosis · Dronabinol · Clinical trial

\section{Abstracts}

Treatment of neuropathic pain (NP) symptoms associated with multiple sclerosis (MS) is frequently insufficient. Yet, cannabis is still rarely offered for treatment of pain. This clinical trial aimed at showing the positive benefit-risk ratio of dronabinol. Two hundred forty MS patients with central NP entered a 16-weeks placebo-controlled phase-III study followed by a 32-weeks open-label period. One hundred patients continued therapy for overall up to 119 weeks. Primary endpoint was change of pain intensity on the 11-point Numerical Rating Scale over a 16-weeks treatment period. Safety was assessed on the basis of adverse reactions (ARs), signs of dependency and abuse. Pain intensity during 16-weeks dronabinol and placebo treatment was reduced by 1.92 and 1.81 points without significant difference in between $(p=0.676)$. Although the proportion of patients with ARs was higher under dronabinol compared to placebo (50.0 vs. $25.9 \%$ ), it decreased during long-term use of dronabinol

\begin{tabular}{ll}
\hline KARGER & ( 2017 The Author(s) \\
& Published by S. Karger AG, Basel \\
E-Mail karger@karger.com & This article is licensed under the Creative Commons Attribution- \\
www.karger.com/ene & NonCommercial-NoDerivatives 4.0 International License (CC BY- \\
NC-ND) (http://www.karger.com/Services/OpenAccessLicense). \\
Usage and distribution for commercial purposes as well as any dis- \\
tribution of modified material requires written permission.
\end{tabular}

(26\%). No signs of drug abuse and only one possible case of dependency occurred. The trial results demonstrate that dronabinol is a safe long-term treatment option.

(c) 2017 The Author(s)

Published by S. Karger AG, Basel

\section{Introduction}

Cannabis and its derivatives have a long tradition in medical use to treat a wide range of indications. Cannabinoids act primarily upon $\mathrm{CB}_{1}$ and $\mathrm{CB}_{2}$ receptors mainly located in the central nervous system and other tissues like lungs, liver and immune cells.

Analgesia is one of the pharmacological actions of cannabinoids. Medical cannabis and its purified active compounds, particularly (-)trans- $\Delta$ 9-tetrahydrocannabinol (dronabinol), may therefore be used for treatment of chronic pain $[1,2]$. There is still a high unmet medical need for treatment of central neuropathic pain (CNP) caused by autoimmune disorders like multiple sclerosis (MS) [3-5]. For a subgroup of CNP patients, pain relief is insufficient or intolerable side effects occur under estab-
Dr. med. Sebastian Schimrigk

Klinikdirektor Klinik für Neurologie

Märkische Kliniken GmbH, Klinikum Lüdenscheid

Paulmannshöher Str. 14, DE-58515 Lüdenscheid (Germany)

E-Mail Sebastian.Schimrigk@klinikum-luedenscheid.de 


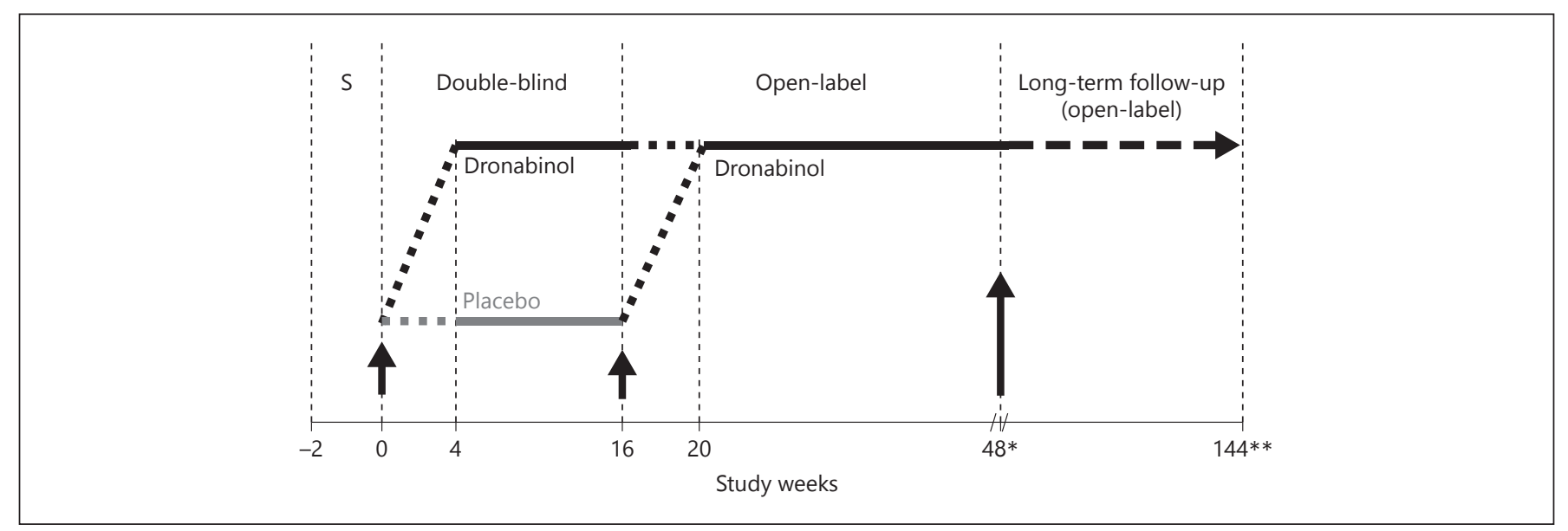

Fig. 1. After the 2-week screening period (S) patients were randomized and included in a double-blind period, including a 4-week titration period (dashed line) in which patients established their individual tolerable dose (maximum $15 \mathrm{mg}$ /day dronabinol or placebo), followed by a maintenance period of 12 weeks. Afterwards, patients entered an open-label period including a doubledummy 4-week titration period (dashed line) followed by a 32week maintenance period. A subgroup continued dronabinol ther-

lished oral treatment options like tricyclic antidepressants, serotonin-noradrenaline reuptake inhibitors, calcium-channel $\alpha_{2}-\delta$ ligands and opioids $[3,4]$. In this indication, severalclinicaltrialswithcannabis-based therapeutics (containing dronabinol and/or cannabidiol [CBD]) have been performed. A short-term clinical trial by Svendsen et al. [6] showed that dronabinol has a clinically relevant analgesic effect with good tolerability. Rog et al. [7] provided evidence for a safe and effective reduction of pain and sleep disturbance after 4 weeks treatment with cannabis-based medicine containing dronabinol and CBD. Langford et al. [8] failed to show efficacy of an oromucosal dronabinol/CBD spray in patients treated for 33 weeks, whereas the occurrence of adverse events (AEs) was similar for verum and placebo. Clinical trials investigating various indications showed long-term effects of cannabisbased medicine. These studies lasting from 38 weeks to 3.5 years showed no major safety concerns and a generally good tolerability [9-16]. Nevertheless, the medical use of cannabis is controversially discussed. Especially, the debate about psychotropic side effects, drug abuse and dependency potential is still ongoing and sufficient data enabling a detailed risk evaluation are not available.

In order to address these open safety issues, we performed a clinical trial to show efficacy and long-term safety of dronabinol in the treatment of patients with MS and CNP.

Dronabinol for Neuropathic Pain apy within an open-label long-term safety follow-up planned to last up to 96 weeks. The start of each new period is indicated with an arrow. * Some patients did not directly enter the long-term follow-up but had a short break (planned duration $\leq 31$ days) before continuing the treatment. ${ }^{* *}$ Due to the nonsignificant efficacy result, long-term safety follow-up was prematurely terminated resulting in a maximum treatment duration of 119 weeks.

\section{Methods}

The study has been registered in US and EU clinical trial databases (NCT00959218; 2006-004255-38) and was approved by German and Austrian competent authorities and applicable Ethics Committees. All patients gave written informed consent prior to inclusion.

\section{Patients}

Eligible patients were aged 18-70 years, met the McDonald criteria [17] for definite MS and had stable disease symptoms and moderate to severe CNP at maximal pain area for at least 3 months as reported by patients (Numerical Rating Scale [NRS] for pain $\geq 4$ ). CNP was defined as initiated or caused by a primary lesion or dysfunction of the central nervous system. Main exclusion criteria were any peripheral pain syndromes, preexisting psychotic disorders, severe cardiac diseases, or known substance abuse. Continuing therapy with amitriptyline and gabapentin, if started at least 3 months ago with a stable dose and oral intake of tramadol as rescue medication for acute pain attacks, was allowed. Neither rescue medication nor a restriction of concomitant medication was intended for long-term follow-up. Investigators were neurologists or pain specialists experienced in treating MS who obtained standardized training regarding MS and pain diagnosis before trial participation.

\section{Study Design}

The first period lasted 16 weeks and had a randomized, doubleblind, placebo-controlled parallel group design followed by a 32 weeks open-label period (Fig. 1). A subgroup of patients participated in the open-label long-term safety follow-up for up to an additional 96 weeks. Double-blind and open-label period started 
with a 4 weeks titration period to establish the patient-specific tolerable dose. Dosing was increased every 5 days by $2.5 \mathrm{mg}$ to reach a daily dose between 7.5 and $15.0 \mathrm{mg}$.

\section{Treatment Allocation}

In the first period, patients were randomly allocated either to dronabinol or placebo in a 1:1 ratio according to a computer-generated randomization code. Block packs with 4 kits were distributed to the sites and kits were allocated to patients in chronological order starting with the lowest available medication number at each site.

Blinding of patients, investigators and staff involved in the conduct of the study was maintained throughout the clinical trial.

\section{Outcomes}

Efficacy Parameters

Main efficacy outcome tools were the 11-point NRS for pain intensity $(0=$ no pain to $10=$ strongest pain imaginable $)$ and the SF-36 quality of life (QoL) questionnaire $[18,19]$.

Primary endpoint of the double-blind period was mean change from baseline pain intensity to mean weekly pain scores within a maximum of 16 weeks. Patients' retrospective rating of pain intensity during week 1 served as baseline value. Patients assessed the NRS daily in the diary during double-blind and open-label period and once every 4 weeks during long-term follow-up.

Patients assessed their QoL at randomization, after 16 and 48 weeks treatment. During long-term follow-up, QoL was assessed at the beginning, every 24 weeks and at the end of treatment.

\section{Safety Parameters}

For safety analysis, vital signs, laboratory parameters, (serious) AEs (SAEs) including (serious) adverse reactions (SARs) were regularly assessed during all 3 periods. ECG recordings were performed prior to randomization to exclude patients with severe cardiac disease, at weeks 56, weeks 96 and at the end of treatment for safety assessment. All AEs were classified according to MedDRA (version 12.0).

Furthermore, patients rated the global tolerability on a 4 -point rating scale ( $1=$ very good to $4=$ poor). If study medication intake was interrupted, the investigator documented withdrawal symptoms such as restlessness, irritability, sleep interference, decreased appetite, excessive sweating, or other drug-dependence-related symptoms. During long-term followup, drug dependence and abuse were documented at the beginning, every 24 weeks and at the end of treatment. Drug dependence and abuse were documented via enquiries in the case report form. The investigator documented if the patient experienced craving for dronabinol, apart from desiring therapeutic effects. Furthermore, he documented if the patient took repeatedly and independently, considerably higher doses than designated to achieve a pleasurable feeling like euphoria or intoxication. These incidences were rated as signs for dependence and abuse. Consumption of dronabinol was analyzed based on bottle weight.

\section{Sample Size Determination}

Sample size calculation was based on the trial conducted by Svendsen et al. [6]. An effect size of $\varepsilon=1 / 2.4=0.42$ was expected for the primary endpoint. Assuming a mean group difference $\mathrm{d}=$ 1.0 and a standard deviation $\mathrm{s}=2.4$, a group sample size of $(n=91)$ patients (test-power $>80 \%$; type I error $\alpha=0.05$ ) was calculated. With regard to the number of drop-outs, the patient number per treatment was 120 .

\section{Statistical Analysis}

Evaluation of safety and tolerability is based on the safety evaluable population (SEP) and compared descriptively between treatment groups. Efficacy parameters are based on the full analysis set (FAS).

Based on the mean weekly pain intensities (NRS) derived from patients' daily assessments, the primary endpoint average change from baseline was calculated. Treatment difference was evaluated with a 2 -sample $t$ test ( $\alpha=0.05 ; 2$-sided; $95 \% \mathrm{CI}$ ).

Absolute changes of SF-36 total score from baseline were calculated and analyzed by a Wilcoxon-Rank sum test. Descriptive statistical details are available for each item, subscale and summary measure.

Results are mean values including SD.

\section{Results}

\section{Demographic Data and Baseline Characteristics}

The clinical trial was performed between June 2007 and March 2010. The SEP included 240 patients (verum: 124, placebo: 116; Fig. 2). In the double-blind and first open-label period, the FAS comprised 238 patients (verum: 124, placebo: 114). The long-term follow-up period included 100 patients in the SEP and 99 in the FAS.

There were no relevant differences between the 2 treatment groups regarding baseline demographic data. The mean age at randomization was $47.7 \pm 9.7$ years, and $72.9 \%$ were female (Table 1). NRS baseline values were $6.4 \pm 1.49$ (verum) and $6.74 \pm 1.41$ (placebo). At the beginning of the open-label period, pain intensity of patients previously being treated with placebo was $4.92 \pm 2.04$ and $4.48 \pm 2.04$ for patients previously receiving verum. $\mathrm{Pa}$ tients' mean age during long-term follow-up was $48.4 \pm$ 9.1 years and $72.0 \%$ were female; the mean NRS at beginning was $3.4 \pm 2.1$.

During the double-blind period, $39.5 \%$ of patients in the verum and $44.0 \%$ in the placebo group took allowed coanalgesics, most frequently gabapentin ( $20.8 \%$ of patients). In addition to their already established concomitant medication, $15.5 \%$ of patients required additional analgesic therapy during the open-label period. During long-term follow-up, 32 patients (32\%) took analgesics as concomitant medication, including 26 patients taking gabapentin.

\section{Efficacy Results}

The primary endpoint "mean change of pain intensity from baseline to mean of weeks 1-16" compared between dronabinol $(1.92 \pm 2.01 ; 30 \%)$ and placebo $(1.81 \pm 1.94$; 


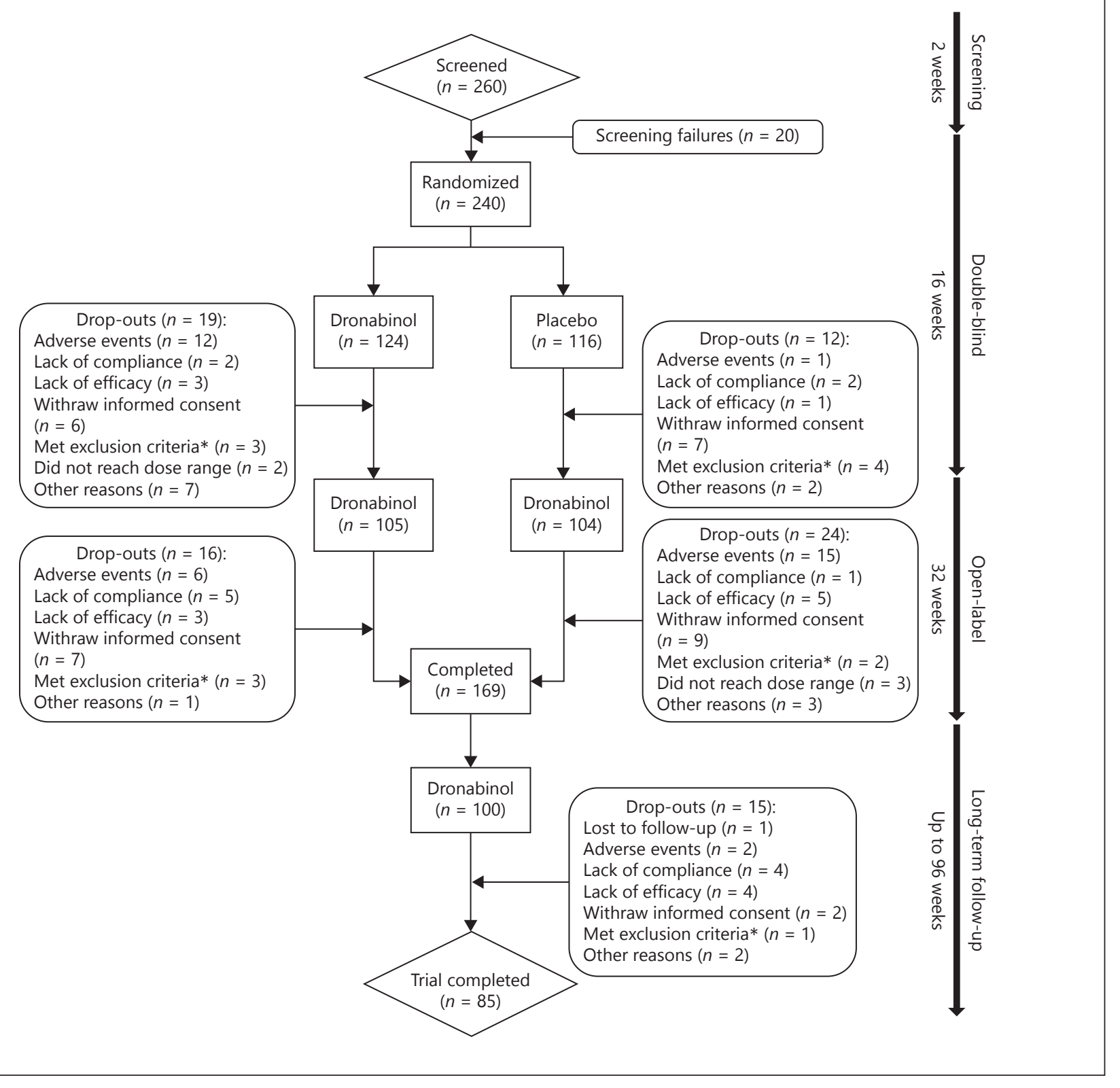

Fig. 2. Patients' allocation to treatment groups in different study periods is displayed. In the middle part, the patient numbers for each period per treatment group are given. On the left and right side the reasons for drop-outs are listed (multiple reasons for one

27\%) was not statistically significant ( $p=0.6760$; Fig. 3). The observed pain reduction was clinically relevant in both groups [19]. During long-term follow-up, pain intensities remained at a low level (range 2.5-3.8).

Correspondingly, the QoL assessment (SF-36) showed a clear improvement during the double-blind period from baseline until end of treatment in both groups patient possible). The arrows on the right indicate the different study periods and their duration. ${ }^{*}$ Criteria appearing after randomization, which represent exclusion criteria for example, intake of disallowed concomitant medication. 
Fig. 3. The mean weekly pain intensities (NRS) are displayed for the double-blind (weeks 0-16) and open-label period (weeks 16-48). At the beginning of each period, a titration period of 4 weeks (T1, T2) was performed. The mean weekly pain intensities decreased substantially during the first 16 weeks and continued to decrease in the open-label period.

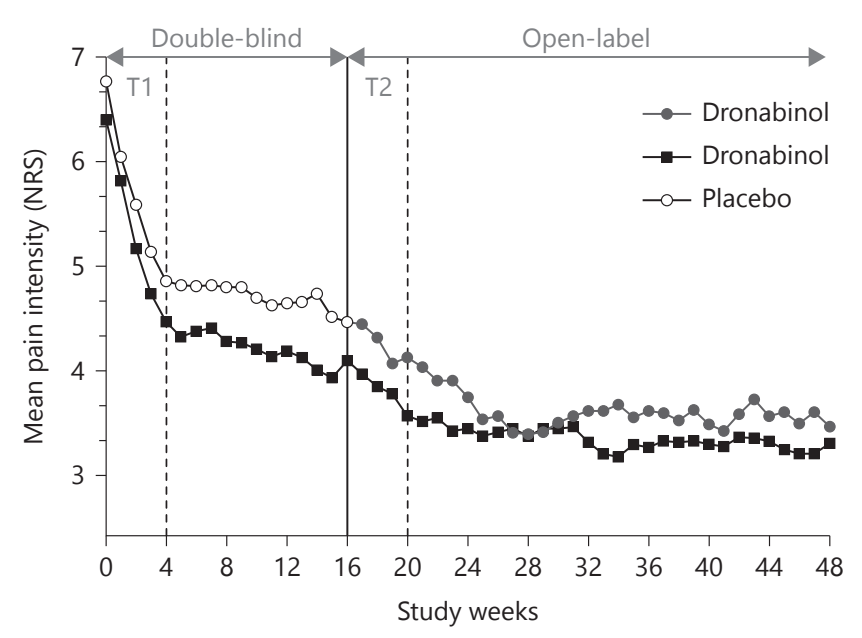

Table 1. Patients' demographic data and baseline characteristics of the safety evaluable population

\begin{tabular}{|c|c|c|c|}
\hline Parameters & Verum $(n=124)$ & Placebo $(n=116)$ & Total $(n=240)$ \\
\hline Gender, male/female, $n(\%)$ & $36(29.0) / 88(71.0)$ & $29(25.0) / 87(75.0)$ & $65(27.1) / 175(72.9)$ \\
\hline \multicolumn{4}{|l|}{ Age, years } \\
\hline Mean (SD) & $48.4(9.6)$ & $47.0(9.7)$ & $47.7(9.7)$ \\
\hline Range & $21.0-67.0$ & $23.4-68.0$ & $21.0-68.0$ \\
\hline \multicolumn{4}{|l|}{ Height, cm } \\
\hline Mean (SD) & $170.9(8.8)$ & $168.0(7.8)$ & $169.5(8.5)$ \\
\hline Range & $155.0-199.0$ & $150.0-187.0$ & $150.0-199.0$ \\
\hline \multicolumn{4}{|l|}{ Weight, kg } \\
\hline Mean (SD) & $73.3(15.8)$ & $70.1(14.9)$ & $71.8(15.4)$ \\
\hline Range & $44.0-130.0$ & $43.5-120.0$ & $43.5-130.0$ \\
\hline \multicolumn{4}{|l|}{ EDSS (score points) } \\
\hline Mean (SD) & $5.0(1.5)$ & $4.9(1.6)$ & n.a. \\
\hline Range & $3.0-8.0$ & $3.0-8.0$ & $3.0-8.0$ \\
\hline \multicolumn{4}{|c|}{ Time since MS diagnosis, months } \\
\hline Mean (SD) & $130.4(95.8)$ & $138.1(98.0)$ & n.a. \\
\hline Range & $6.0-467.0$ & $3.0-481.0$ & $3.0-481.0$ \\
\hline \multicolumn{4}{|c|}{ Time since CNP diagnosis, months } \\
\hline Mean (SD) & $54.0(53.8)$ & $59.5(58.1)$ & n.a. \\
\hline Range & $2.0-357.0$ & $4.0-419.0$ & $2.0-419.0$ \\
\hline
\end{tabular}

CNP, central neuropathic pain; EDSS, expanded disability status scale; MS, multiple sclerosis; n.a., not available.

\section{Safety Results}

Dronabinol Dosage

Patients were exposed to a dronabinol mean daily dose of $12.7 \pm 2.9 \mathrm{mg}$ (range $0-15.9 \mathrm{mg}$ ) for a mean duration of $382.0 \pm 234.6$ days (range $0-831$ days).

During long-term follow-up, 19 patients increased and 24 decreased their dose temporarily (multiple counting possible), 63 patients did not change their dose.
(Serious) Adverse Events, (Serious) Adverse

Reactions

During double-blind and open-label period $92.9 \%$ of patients experienced at least one AE.

In the double-blind period, the proportion of patients experiencing AEs was higher in the dronabinol group than in the placebo group (Table 2). The proportion of patients experiencing SAEs was low. ARs 
Table 2. Summary of AEs ${ }^{\mathrm{a}}$, SAEs, $\mathrm{ARs}^{\mathrm{b}}$, and SARs during double-blind, open-label, and long-term follow-up period

\begin{tabular}{|c|c|c|c|c|}
\hline & \multicolumn{2}{|c|}{$\begin{array}{l}\text { Double-blind period } \\
16 \text { weeks }\end{array}$} & \multirow{2}{*}{$\begin{array}{l}\text { Open-label period } \\
32 \text { weeks } \\
\begin{array}{l}\text { Verum } \\
(n=209)\end{array}\end{array}$} & \multirow{2}{*}{$\begin{array}{l}\begin{array}{l}\text { Long-term follow-up } \\
\text { to } 69 \text { weeks }\end{array} \\
\text { Verum } \\
(n=100)\end{array}$} \\
\hline & $\begin{array}{l}\text { Verum } \\
(n=124)\end{array}$ & $\begin{array}{l}\text { Placebo } \\
(n=116)\end{array}$ & & \\
\hline Patients with AEs, $n(\%)$ & $109(87.9)$ & $85(73.3)$ & $174(83.3)$ & $79(79)$ \\
\hline AEs, $n$ & 381 & 248 & 736 & 387 \\
\hline Patients with ARs, $n(\%)$ & $62(50.0)$ & $30(25.9)$ & $83(39.7)$ & $26(26)$ \\
\hline ARs, $n$ & 144 & 59 & 201 & 53 \\
\hline ARs of AEs, $\%$ & 37.8 & 23.8 & 27.3 & 13.7 \\
\hline Patients with SAEs, $n(\%)$ & $12(9.7)$ & $7(6.0)$ & $29(13.9)$ & $13(13)$ \\
\hline SAEs, $n$ & 17 & 10 & 47 & 23 \\
\hline SAEs of AEs, $\%$ & 4.5 & 4.0 & 6.4 & 5.9 \\
\hline Patients with SARs, $n(\%)$ & $1(0.8)$ & $0(0.0)$ & $2(1.0)$ & $0(0)$ \\
\hline SARs, $n$ & 2 & 0 & 2 & 0 \\
\hline SARs of ARs, \% & 1.4 & 0.0 & 1.0 & 0.0 \\
\hline
\end{tabular}

AE, adverse event; AR, adverse reaction; SAE, serious adverse event; SAR, serious adverse reaction.

${ }^{a}$ AEs are all harmful events that occur during a trial whether related or not related to the study drug.

${ }^{\mathrm{b}}$ ARs are harmful events at least possibly related to the study drug as judged by the investigator.

were more frequently observed in the verum group compared to the placebo group. SARs were very rare and occurred only in 3 patients (dysphoria, constipation, exacerbation of preexisting neuropathic pain, NP; Table 2).

During the open-label period, patients switching from placebo to verum experienced more AEs than patients continuing verum treatment (407 vs. 329 ). This imbalance is also reflected by the proportion of patients with ARs being higher for patients switching to dronabinol (46.6\%) than for patients continuing dronabinol treatment (23.4\%). Despite the longer duration compared to the first 32-weeks open-label period, the number of AEs was lower in the long-term follow-up (Table 2). Thirtysix patients discontinued the study due to AEs of which 26 were judged as possibly related ( 1 patient under placebo) and 7 of these AEs were serious. Only 2 out of these 36 patients prematurely terminated the trial during longterm follow-up (Fig. 2). Of the 53 ARs during long-term follow-up, 16 ARs recovered, 4 ARs recovered with sequelae, 26 ARs were still ongoing and in 8 ARs, the outcome was unknown at database lock. No deaths occurred during the trial.

Most AEs and ARs occurred during the 4-weeks titration periods of either the double-blind or open-label period due to titration to the maximum tolerable dose (Fig. 4). Furthermore, patients on verum already during the double-blind period had a considerable increase of AEs and ARs during the second titration with placebo (double dummy, weeks 17-20, Fig. 4a). There was no time course dependency for SAEs and SARs occurrence (Fig. 4).

The most common ARs under dronabinol were similar for the first 2 trial periods but changed during longterm treatment (Table 3 ).

Global Assessment of Tolerability

Patients assessed the global tolerability mostly as very good or good after all 3 trial periods (double-blind period: verum: $84.5 \%$; placebo: $95.6 \%$; open-label period: $85.2 \%$; follow-up period: $93 \%)$.

\section{Vital Signs, ECG}

During the double-blind and open-label period, no clinically relevant changes in the vital signs blood pressure, heart rate and weight were observed. Both blood hematology and biochemistry analysis did not reveal any clinically relevant differences or trends. During longterm follow-up, vital parameters were unremarkable and there were no clinically relevant laboratory abnormalities. The presence of severe cardiac diseases could definitely be ruled out clinically and by ECG for $90 \%$ of patients at the end of treatment. Data of $8 \%$ of patients were missing. 
Table 3. Summary of the most common ARs in the double-blind and open-label period (cut of $\geq 5 \%$ of all ARs)

\begin{tabular}{|c|c|c|c|c|}
\hline \multirow[t]{2}{*}{$\begin{array}{l}\text { Preferred term }{ }^{\mathrm{a}} \\
n[\% \text { of all ARs] }\end{array}$} & \multicolumn{2}{|c|}{$\begin{array}{l}\text { Double-blind period } \\
16 \text { weeks }\end{array}$} & \multirow{2}{*}{$\begin{array}{l}\text { Open-label period } \\
32 \text { weeks } \\
\text { Verum } \\
(n=209)\end{array}$} & \multirow{2}{*}{$\begin{array}{l}\text { Long-term follow-up } \\
\text { up to } 69 \text { weeks } \\
\text { Verum } \\
(n=100)\end{array}$} \\
\hline & $\begin{array}{l}\text { Verum } \\
(n=124)\end{array}$ & $\begin{array}{l}\text { Placebo } \\
(n=116)\end{array}$ & & \\
\hline Overall number of ARs & 144 & 59 & 201 & 53 \\
\hline Dizziness & $25(17.4)$ & $5(8.5)$ & $25(12.4)$ & $2(3.8)$ \\
\hline Vertigo & $14(9.7)$ & $3(5.1)$ & $20(10.0)$ & - \\
\hline Fatigue & $10(6.9)$ & $5(8.5)$ & $15(7.5)$ & $6(11.3)$ \\
\hline Dry mouth & $9(6.3)$ & $1(1.7)$ & $4(2.0)$ & - \\
\hline Adverse drug reaction & $8(5.6)$ & - & $6(3.0)$ & $1(1.9)$ \\
\hline Nausea & $6(4.2)$ & $4(6.8)$ & $11(5.5)$ & - \\
\hline Headache & $5(3.5)$ & $6(10.2)$ & $4(2.0)$ & - \\
\hline Diarrhoea & $3(2.1)$ & - & $10(5.0)$ & - \\
\hline Withdrawal syndrome & - & - & $10(5.0)$ & $9(17.0)$ \\
\hline Neuralgia & - & - & $2(1.0)$ & $5(9.4)$ \\
\hline Insomnia & $1(0.7)$ & - & $1(0.5)$ & $3(5.7)$ \\
\hline
\end{tabular}

AR, adverse reaction.

${ }^{a}$ ARs that could not be adequately represented by a single MedDRA preferred term were divided in different preferred terms resulting in more ARs coded and counted than reported.

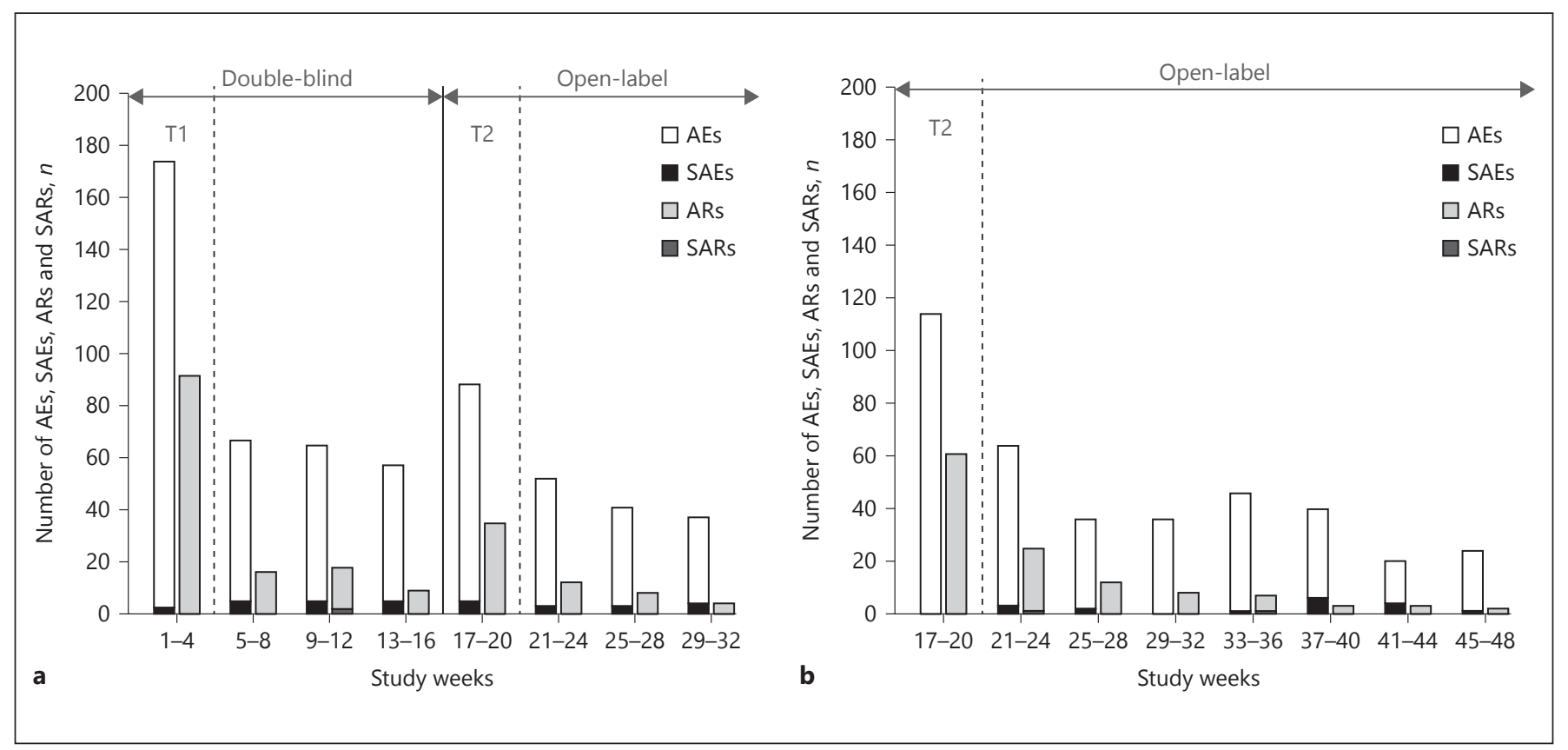

Fig. 4. Dronabinol-induced (serious) adverse events (SAEs) and (serious) adverse reactions (SARs) are illustrated by the time of occurrence. Overall, the number of AEs and ARs decreased over time with no time dependency for SAEs and SARs occurrence. a shows the time course of SAEs and SARs for patients receiving dronabinol during the double-blind and open-label period for the first 32 weeks of treatment. Most AEs and ARs occurred during the first titration period (T1, weeks 1-4, dronabinol titration) and during second titration (T2, weeks 17-20, double-dummy placebo titration). $\mathbf{b}$ shows the time course of SAEs and SARs for patients switched from placebo to dronabinol starting from the first week of dronabinol intake (week 17). Most AEs and ARs occurred during the titration period (T2, weeks 17-20, dronabinol titration). 
Signs of Withdrawal

For most patients, no withdrawal reactions were reported after cessation of study medication: withdrawal symptoms were reported only for 6 patients after the open-label period and 4 patients after the long-term follow-up (Table 3). Symptoms described were sleep disturbances, excitability, nervousness and increase of NP.

\section{Drug Dependency and Drug Abuse}

Diagnostic criteria of drug dependency and abuse were regularly assessed by investigators during the longterm follow-up period. Mild signs of drug dependency were documented only for 1 patient. No patient showed any sign of drug abuse.

\section{Discussion}

This clinical trial demonstrates a clinically relevant decrease of mean pain intensities during 16-weeks dronabinol and placebo treatment, without reaching a statistical significant difference between both groups.

Despite overall treatment with dronabinol lasting up to 119 weeks, occurrence of severe and serious ARs was rare. Although the rate of ARs was higher under dronabinol compared to placebo during the first 16 weeks, the proportion of patients affected by ARs decreased to $26 \%$ during long-term follow-up.

These results reveal that dronabinol is a safe long-term treatment option, which causes a similar number of side effects in patients with MS and CNP in comparison to standard treatment.

A previous clinical trial performed by Svendsen et al. [6] with dronabinol showed its efficacy superiority over placebo. Other therapeutic drugs recommended by guidelines for the condition CNP are often no more effective in reducing pain than dronabinol [20-29]. However, for some substances, clinical trials demonstrated superiority over placebo.

Besides the analgesic effect of dronabinol, the sedative, spasmolytic, anti-inflammatory and anxiolytic effects $[30,31]$ may contribute to improve QoL of NP patients, which is the overall therapeutic goal. Interestingly, QoL assessment showed a relevant improvement during the first 16 weeks in both treatment groups. The long-term follow-up revealed no remarkable deterioration in SF-36 single items over time. In contrast, 2 clinical trials in patients with CNP due to spinal cord injury with standard treatment, one with pregabalin and one with duloxetine, showed a significant improvement only of the SF-36 pain domain, whereas condition of some other domains even deteriorated $[23,27]$. These results underline the positive and comprehensive influence of dronabinol on patients' overall QoL.

Patients' QoL may also be affected by side effects, which are in general quite common for centrally acting substances. In our study, the proportion of patients with ARs was highest in the beginning and declined during dronabinol treatment. The initially high number of ARs is due to the titration period and the assumed high expectations of patients [32], a phenomenon that was also observed in another clinical trial with dronabinol [6].

Most AEs and ARs were non-serious and of mild to moderate intensity. Safety data of trials with medications currently used for treatment of CNP show that they are partly even more harmful than dronabinol $[20,21,25,26$, $28,29]$.

In our trial, the most frequent ARs belonged to the SOC "nervous system disorders" followed by "general disorders and administration site conditions". A comparison of our safety results with other studies is challenging because both coding of AEs and causal relationship to study medication are often missing or are published intransparently. Nevertheless, comprehensive evaluation of available data shows that pregabalin is mostly affecting the same SOCs and furthermore having possible systemic side effects [20,33,34]. Taken together, the variety of side effects induced by different treatment options [20, $25,27,29,33-35]$ should lead the physician to make a decision on a case-by-case basis, in particular for combination therapies.

For chronic pain conditions, short-term side effects alone may not play a role; even tolerance, addiction and withdrawal symptoms possibly become present as a result of long-term use. Smith [36] raised some concerns about possible long-term side effects of cannabinoids such as tolerance and addiction. The assessment of dronabinol's potential to induce withdrawal symptoms, dependency, abuse and tolerance during long-term follow-up of our trial revealed no negative hints. Despite the long duration of dronabinol intake, a low number of only 10 patients showed transient withdrawal symptoms. Furthermore, there was no evidence of abuse and only 1 patient showed mild signs of dependency. The intake of a relative stable dose of dronabinol over a long period suggests that there is no tolerance development.

Other medications currently used in this indication, such as pregabalin and opioids, have a higher potential for abuse and dependency and may also cause withdrawal symptoms after discontinuation of treatment $[34,37]$. 
Physicians need to face this problem when prescribing medications, in particular, for long-term use.

Trial design and in- and exclusion criteria followed the "Guideline on Clinical Investigation of Medicinal Products Intended for the Treatment of Neuropathic Pain" being available at the time of study conduct [38]. The long-term follow-up of this trial was even longer than recommended (up to 69 instead of 52 weeks). Nevertheless, the trial had some limitations. Since the study was conducted there have been new insights about different pain types in MS patients. Besides, NP caused by damage to nerves in the brain and spinal cord patients are troubled with nociceptive pain induced by damage to muscles, tendons, ligaments and soft tissues [39]. Special subtypes like myofascial pain contribute to a complex picture, which might impede patients' correct differentiation and evaluation of pain. Meanwhile, the definition for CNP of the International Association for the Study of Pain as used in this trial is seen controversial due to the lack of defined boundaries. NP is now redefined as "pain arising as a direct consequence of a lesion or disease affecting the somatosensory system" [40]. Available literature confirmed the selected dose limit of $15 \mathrm{mg}[6,41]$. Nevertheless, it seems to be insufficient because in our study, $72.5 \%$ of the patients titrated up to this limit during the double-blind period. In future, higher dose limits should be considered. A further limitation of the trial is the pronounced placebo analgesia, which is mediated by similar neurobiological systems as targeted by specific pharmacological treatments. Contribution of the endogenous cannabinoid system to placebo analgesia has also been suggested [42]. It is known that expectations, behavioural conditioning and a close patient-physician relationship increase placebo responses $[32,43]$. All these parameters might be influenced by study conditions. A meta-analysis of placebo responses in CNP revealed a significant pain reduction by placebo [44]. A further risk of the double-blind period is the risk of unmasking treatment allocation by patients who were already familiar with the use of cannabinoids. To avoid unmasking, patients who used dronabinol within 1 year or marihuana within the last 4 weeks before study start were excluded from the study. A nocebo effect, that is, negative expectation regarding a pharmaceutical drug causing AEs unrelated to specific pharmacological actions, was observed during placebo titration in the open-label period, which is probably indicating a sustained blinding of patients.

Overall, this trial demonstrated the long-lasting therapeutic potential, the good tolerability and favourable safety profile of dronabinol - especially in terms of drug abuse and dependency. Based on the presented results, there is no special focus on the harm caused by dronabinol treatment. Although the statistical proof of efficacy for dronabinol versus placebo treatment is pending, physicians should consider the potential benefits of the multifactorial effects of dronabinol.

\section{Acknowledgement}

We are grateful to all participating clinical sites for their commitment and successful conduct of this clinical trial.

\section{Disclosure Statement}

One or more of the authors has declared the following potential conflict or source of funding. The present study was funded by $\mathrm{Bi}$ onorica research GmbH (Innsbruck, Austria). C.N., E.M.K., G.W., and D.A.-S. are employees of Bionorica SE, Germany. S.S. has received grant support and speaker honoraria from Bayer vital, Bionorica, Biogen, BMS, DIAMED, Genzyme, Novartis, Pfizer, Teva. M.M. has received lecture fees, travel grants and honoraria for consulting from Bayer Health Care AG, Biogen GmbH, Bionorica, Merck Serono, Novartis Pharma GmbH, Sanofi-Aventis (Genzyme), and Teva.

\section{References}

1 Kowal MA, Hazekamp A, Grotenhermen F: Review on clinical studies with cannabis and cannabinoids 2010-2014. Cannabinoids 2016;11:1-18

2 Grotenhermen F, Muller-Vahl K: The therapeutic potential of cannabis and cannabinoids. Dtsch Arztebl Int 2012;109:495-501.

3 Dworkin RH, O'Connor AB, Audette J, Baron R, Gourlay GK, Haanpaa ML, Kent JL, Krane EJ, Lebel AA, Levy RM, Mackey SC, Mayer J, Miaskowski C, Raja SN, Rice AS, Schmader KE, Stacey B, Stanos S, Treede RD, Turk DC, Walco GA, Wells CD: Recommendations for the pharmacological management of neuropathic pain: an overview and literature update. Mayo Clin Proc 2010;85(3 suppl):S3S14.

4 Finnerup NB, Attal N, Haroutounian S, McNicol E, Baron R, Dworkin RH, Gilron I, Haanpaa M, Hansson P, Jensen TS, Kamerman PR, Lund K, Moore A, Raja SN, Rice AS, Rowbotham M, Sena E, Siddall P, Smith BH, Wallace M: Pharmacotherapy for neuropathic pain in adults: a systematic review and meta-analysis. Lancet Neurol 2015;14:162173.
5 Torrance N, Ferguson JA, Afolabi E, Bennett MI, Serpell MG, Dunn KM, Smith BH: Neuropathic pain in the community: more undertreatedthan refractory? Pain 2013;154:690-699.

6 Svendsen KB, Jensen TS, Bach FW: Does the cannabinoid dronabinol reduce central pain in multiple sclerosis? Randomised double blind placebo controlled crossover trial. BMJ 2004;329:253.

7 Rog DJ, Nurmikko TJ, Friede T, Young CA: Randomized, controlled trial of cannabisbased medicine in central pain in multiple sclerosis. Neurology 2005;65:812-819. 
8 Langford RM, Mares J, Novotna A, Vachova M, Novakova I, Notcutt W, Ratcliffe S: A double-blind, randomized, placebo-controlled, parallel-group study of thc/cbd oromucosal spray in combination with the existing treatment regimen, in the relief of central neuropathic pain in patients with multiple sclerosis. J Neurol 2013;260:984-997.

9 Hoggart B, Ratcliffe S, Ehler E, Simpson KH, Hovorka J, Lejcko J, Taylor L, Lauder H, Serpell M: A multicentre, open-label, follow-on study to assess the long-term maintenance of effect, tolerance and safety of THC/CBD oromucosal spray in the management of neuropathic pain J Neurol 2015;262:27-40.

10 Ball S, Vickery J, Hobart J, Wright D, Green C, Shearer J, Nunn A, Cano MG, MacManus D, Miller D, Mallik S, Zajicek J: The cannabinoid use in progressive inflammatory brain disease (CUPID) trial: a randomised doubleblind placebo-controlled parallel-group multicentre trial and economic evaluation of cannabinoids to slow progression in multiple sclerosis. Health Technol Assess 2015; 19:viiviii, xxv-xxxi, 1-187.

11 Flachenecker P, Henze T, Zettl UK: Longterm effectiveness and safety of nabiximols (tetrahydrocannabinol/cannabidiol oromucosal spray) in clinical practice. Eur Neurol 2014;72:95-102.

12 Paolicelli D, Direnzo V, Manni A, D’Onghia M, Tortorella C, Zoccolella S, Di Lecce V, Iaffaldano A, Trojano M: Long-term data of efficacy, safety, and tolerability in a real-life setting of THC/CBD oromucosal spray-treated multiple sclerosis patients. J Clin Pharmacol 2016;56:845-851.

13 Serpell MG, Notcutt W, Collin C: Sativex long-term use: an open-label trial in patients with spasticity due to multiple sclerosis. J Neurol 2013;260:285-295.

14 Beal JE, Olson R, Lefkowitz L, Laubenstein L, Bellman P, Yangco B, Morales JO, Murphy R, Powderly W, Plasse TF, Mosdell KW, Shepard KV: Long-term efficacy and safety of dronabinol for acquired immunodeficiency syndrome-associated anorexia. J Pain Symptom Manage 1997;14:7-14.

15 Zajicek JP, Sanders HP, Wright DE, Vickery PJ, Ingram WM, Reilly SM, Nunn AJ, Teare LJ, Fox PJ, Thompson AJ: Cannabinoids in multiple sclerosis (CAMS) study: safety and efficacy data for 12 months follow up. J Neurol Neurosurg Psychiatry 2005;76:1664-1669.

16 Rog DJ, Nurmikko TJ, Young CA: Oromucosal delta9-tetrahydrocannabinol/cannabidiol for neuropathic pain associated with multiple sclerosis: an uncontrolled, open-label, 2-year extension trial. Clin Ther 2007;29:20682079.

17 McDonald WI, Compston A, Edan G, Goodkin D, Hartung HP, Lublin FD, McFarland $\mathrm{HF}$, Paty DW, Polman $\mathrm{CH}$, Reingold SC, Sandberg-Wollheim M, Sibley W, Thompson A, van den Noort S, Weinshenker BY, Wolinsky JS: Recommended diagnostic criteria for multiple sclerosis: guidelines from the inter- national panel on the diagnosis of multiple sclerosis. Ann Neurol 2001;50:121-127.

18 Bullinger M: German translation and psychometric testing of the SF-36 health survey: preliminary results from the IQOLA project. International quality of life assessment. Soc Sci Med 1995;41:1359-1366.

19 Farrar JT, Young JP Jr, LaMoreaux L, Werth JL, Poole RM: Clinical importance of changes in chronic pain intensity measured on an 11-point numerical pain rating scale. Pain 2001;94:149-158.

20 Cardenas DD, Nieshoff EC, Suda K, Goto S, Sanin L, Kaneko T, Sporn J, Parsons B, Soulsby M, Yang R, Whalen E, Scavone JM, Suzuki MM, Knapp LE: A randomized trial of pregabalin in patients with neuropathic pain due to spinal cord injury. Neurology 2013;80:533539.

21 Siddall PJ, Cousins MJ, Otte A, Griesing T, Chambers R, Murphy TK: Pregabalin in central neuropathic pain associated with spinal cord injury: a placebo-controlled trial. Neurology 2006;67:1792-1800.

22 Kim JS, Bashford G, Murphy TK, Martin A, Dror V, Cheung R: Safety and efficacy of pregabalin in patients with central post-stroke pain. Pain 2011;152:1018-1023.

23 Vranken JH, Dijkgraaf MG, Kruis MR, van der Vegt MH, Hollmann MW, Heesen M: Pregabalin in patients with central neuropathic pain: a randomized, double-blind, placebo-controlled trial of a flexible-dose regimen. Pain 2008;136:150-157.

24 Hesami O, Gharagozli K, Beladimoghadam N, Assarzadegan F, Mansouri B, Sistanizad M: The efficacy of gabapentin in patients with central post-stroke pain. Iran J Pharm Res 2015;14:95-101.

25 Levendoglu F, Ogun CO, Ozerbil O, Ogun TC, Ugurlu H: Gabapentin is a first line drug for the treatment of neuropathic pain in spinal cord injury. Spine (Phila Pa 1976) 2004;29:743-751.

26 Rintala DH, Holmes SA, Courtade D, Fiess RN, Tastard LV, Loubser PG: Comparison of the effectiveness of amitriptyline and gabapentin on chronic neuropathic pain in persons with spinal cord injury. Arch Phys Med Rehabil 2007;88:1547-1560.

27 Vranken JH, Hollmann MW, van der Vegt MH, Kruis MR, Heesen M, Vos K, Pijl AJ, Dijkgraaf MG: Duloxetine in patients with central neuropathic pain caused by spinal cord injury or stroke: a randomized, double-blind, placebo-controlled trial. Pain 2011;152:267-273.

28 Vollmer TL, Robinson MJ, Risser RC, Malcolm SK: A randomized, double-blind, placebo-controlled trial of duloxetine for the treatment of pain in patients with multiple sclerosis. Pain Pract 2014; 14:732-744.

29 Norrbrink C, Lundeberg T: Tramadol in neuropathic pain after spinal cord injury: a randomized, double-blind, placebo-controlled trial. Clin J Pain 2009;25:177-184.

30 Evans FJ: Cannabinoids: the separation of central from peripheral effects on a structural basis. Planta Med 1991;57:60-67.
31 Pacher P, Batkai S, Kunos G: The endocannabinoid system as an emerging target of pharmacotherapy. Pharmacol Rev 2006;58: 389-462.

32 Pollo A, Amanzio M, Arslanian A, Casadio C, Maggi G, Benedetti F: Response expectancies in placebo analgesia and their clinical relevance. Pain 2001;93:77-84.

33 Zaccara G, Gangemi P, Perucca P, Specchio L: The adverse event profile of pregabalin: a systematic review and meta-analysis of randomized controlled trials. Epilepsia 2011;52:826836.

34 Toth C: Pregabalin: latest safety evidence and clinical implications for the management of neuropathic pain. Ther Adv Drug Saf 2014;5: $38-56$.

35 Mehta S, Guy S, Lam T, Teasell R, Loh E: Antidepressants are effective in decreasing neuropathic pain after SCI: a meta-analysis. Top Spinal Cord Inj Rehabil 2015;21:166-173.

36 Smith PF: Symptomatic treatment of multiple sclerosis using cannabinoids: recent advances. Expert Rev Neurother 2007;7:11571163.

37 Edlund MJ, Martin BC, Russo JE, DeVries A, Braden JB, Sullivan MD: The role of opioid prescription in incident opioid abuse and dependence among individuals with chronic noncancer pain: the role of opioid prescription. Clin J Pain 2014;30:557-564.

38 CPMP/EWP/252/03: Guideline on Clinical Investigation of Medicinal Products Intended for the Treatment of Neuropathic Pain. EMEA, 2004.

39 O'Connor AB, Schwid SR, Herrmann DN, Markman JD, Dworkin RH: Pain associated with multiple sclerosis: systematic review and proposed classification. Pain 2008;137:96111

40 Treede RD, Jensen TS, Campbell JN, Cruccu G, Dostrovsky JO, Griffin JW, Hansson P, Hughes R, Nurmikko T, Serra J: Neuropathic pain: redefinition and a grading system for clinical and research purposes. Neurology 2008;70:1630-1635.

41 Weber J, Schley M, Casutt M, Gerber H, Schuepfer G, Rukwied R, Schleinzer W, Ueberall M, Konrad C: Tetrahydrocannabinol (delta 9-THC) treatment in chronic central neuropathic pain and fibromyalgia patients: results of a multicenter survey. Anesthesiol Res Pract 2009;2009:pii: 827290

42 Benedetti F, Amanzio M, Rosato R, Blanchard C: Nonopioid placebo analgesia is mediated by CB1 cannabinoid receptors. Nat Med 2011; 17:1228-1230.

43 Enck P, Bingel U, Schedlowski M, Rief W: The placebo response in medicine: minimize, maximize or personalize? Nat Rev Drug Discov 2013;12:191-204.

44 Cragg JJ, Warner FM, Finnerup NB, Jensen MP, Mercier C, Richards JS, Wrigley P, Soler D, Kramer JL: Meta-analysis of placebo responses in central neuropathic pain: impact of subject, study, and pain characteristics. Pain 2016;157:530-540. 